\title{
De la relación inter-individual a la relación inter- organizacional: Un análisis de redes multinivel de un mercado de programas de televisión en África subsahariana
}

\author{
Guillaume Favre ${ }^{1}$, Julien Brailly, Josiane Chatellet - Irisso, Université Paris- \\ Dauphine \\ Emmanuel Lazega²- CSO, Sciences- Po, Paris
}

\begin{abstract}
Resumen
Hoy, el encastramiento de las actividades económicas en las relaciones sociales no parece ser un hecho a demostrar en el campo de la sociología económica. Sin embargo, ¿podemos concluir que un contrato comercial entre dos empresas está necesariamente encastrado en las relaciones sociales de sus miembros? Sobre la base de los conceptos de encastramiento y desacoplamiento de White, intentaremos analizar cómo las relaciones inter-individuales pueden convertirse en relaciones inter-organizacionales. El análisis de redes sociales multinivel constituye un marco teórico y metodológico para captar este fenómeno. Describiremos a través del estudio de una red multinivel de un salón de distribución de programas audiovisuales en África, la dinámica entre encastramiento y desacoplamiento que podemos observar en un mercado. Demostramos que en la medida en que los individuos participan más en este salón, más serán los contratos entre las empresas que están encastrados en sus redes.
\end{abstract}

Palabras clave: Relaciones inter-individuales, relaciones inter-organizacionales, redes sociales multinivel

\section{Résumé}

L'encastrement des activités économiques dans les relations sociales ne semble plus aujourd'hui un fait à prouver dans le champ de la sociologie économique. Pourtant, pouvons-nous en conclure qu'un contrat commercial entre deux entreprises est nécessairement encastré dans les relations sociales de leurs membres ? En nous inspirant des concepts d'encastrement et découplage de White, nous chercherons ainsi à analyser comment des relations inter-individuelles peuvent devenir des relations inter-organisationnelles. L'analyse de réseaux sociaux multiniveaux constitue un cadre théorique et méthodologique permettant de saisir ce phénomène. Nous décrirons ainsi à travers une étude de réseau multiniveaux d'un salon de distribution de programmes audiovisuels en Afrique, les dynamiques entre encastrement et découplage observables sur un marché. Nous montrons entre autres que plus les individus participent à ces salons, plus les contrats entre leurs entreprises sont encastrés dans leurs réseaux.

Mots clé : Relations inter-individuelles, relations inter-organisationelles, réseaux sociaux multiniveaux.

\footnotetext{
${ }^{1}$ gfavre29@gmail.com

${ }^{2}$ Este trabajo es una parte del proyecto MLSN (Multi-Level Social Networks) financiados por la ANR (Agence Nationale de Recherche).
} 


\section{Introducción: un enfoque multinivel para la construcción social de los mercados}

La nueva sociología económica ${ }^{3}$ (Swedberg, 1997) ha reflexionado reiteradamente sobre el tema del encastramiento de las actividades económicas en las estructuras sociales. Demostrando la importancia de las redes sociales en los mercados, estos autores destacan la importancia de las estructuras sociales en la aparición de las actividades económicas. Según Granovetter (1985) los individuos no se comportan como átomos en la vida social, su comportamiento no está totalmente dictado por las macro-estructuras, sino que sus acciones dependen de un contexto relacional. En otras palabras, para Granovetter, los fenómenos económicos están encastrados en las estructuras sociales, las redes sociales.

En esta perspectiva una relación económica entre dos organizaciones se encastra en las redes individuales de los distintos miembros y esta relación puede existir porque sus miembros tienen relaciones personales. Un contrato de compra y venta, una asociación de investigación científica o una joint-venture dependen necesariamente de las relaciones inter-individuales entre por lo menos dos miembros de estas dos organizaciones. Si las transacciones entre las empresas están encastradas en redes personales, implica que para comprender estas transacciones, la escala de análisis relevante es la de los individuos más bien que la de las empresas.

En tal perspectiva, sin embargo, no debemos considerar la organización como una simple concatenación de sus miembros. La sociología de las organizaciones ha demostrado que los actores sociales se niegan a ser meros instrumentos al servicio de esta. Los actores interactúan y desarrollan sus propias estrategias sin necesariamente seguir la lógica o los intereses de la empresa (Crozier y Friedberg, 1977 ; Friedberg, 1997). La organización no es un propósito unificado y único, sino un conjunto construido colectivamente.

Desde este punto de vista ¿cómo considerar un contrato entre dos empresas como un conjunto de relaciones entre los individuos? Imaginemos dos importantes organizaciones representadas, respectivamente, por un gerente de ventas y un responsable de adquisición. Estas dos personas tienen la oportunidad de reunirse y ponerse de acuerdo sobre el objeto de la transacción, los aspectos principales del contrato, y posiblemente el precio. El contrato pasa por la dirección de la empresa que da su consentimiento, el departamento legal, que define las modalidades del

\footnotetext{
${ }^{3}$ Los autores desean agradecer a Jaime Montes por su participación intensiva en la traducción de este artículo.
} 
contrato, el servicio técnico que apoyará el envío del material, y luego por el departamento de finanzas que hará la facturación y el seguimiento del pago. Evidentemente, la misma lógica se puede encontrar en el comprador. En resumen, una vez que se alcance un acuerdo entre el comprador y el vendedor, toda la maquinaria organizacional comienza. A partir de este momento, ya no se puede atribuir esta relación a los dos individuos. La relación no deja de ser interindividual, ya que ambos actores siguen en contacto. Son ellos los que iniciaron el contrato y es muy probable que, si debe ser renovado, sería por iniciativa de uno de ellos. Sin embargo, esta relación pasa a una escala inter-organizacional porque involucra a otros actores y sus organizaciones. Por tanto, es necesario mantener e incluso explorar esta dualidad entre las relaciones inter-individuales y interorganizacionales para comprender estas transacciones. Este es el punto que queremos examinar en este artículo.

Examinando este paso entre relación inter-individual y relación inter-organizacional, Grossetti y Bes (2001) utilizan los conceptos de encastramiento y desacoplamiento formulados por Harrison White $(1981,1992)$. El encastramiento se refiere a la disolución de un contexto de interacción en otro: por ejemplo, designa aquí el proceso de disolución de la asociación entre dos empresas en las relaciones de sus miembros. El desacoplamiento por el contrario, designa la autonomisación de un contexto de interacción con respecto a otro: Esto sería similar, en este caso a una abstracción de la relación inter-individual a través de, por ejemplo, una rutinización de las interacciones organizacionales.

Parece necesaria entonces una reflexión que incorpore simultáneamente las relaciones entre individuos y entre organizaciones para comprender este proceso, es decir considerar estos dos tipos de relaciones y estos dos tipos de actores sociales en dos niveles de acción superpuestos e interdependientes. Podemos hablar entonces de análisis multinivel de las relaciones comerciales. En estadística, algunos investigadores han desarrollado modelos originales que combinan ambos efectos, individuales y contextuales, en la perspectiva de hacer una síntesis entre los enfoques holísticos e individualistas. Estos modelos consideran diferentes niveles en los sistemas sociales con el objeto de medir el impacto de cada nivel observando a la vez el individuo y el grupo. Estos análisis multinivel mostraron un fuerte desarrollo durante los últimos veinte años [Bryk y Raudenbush de 1992, Goldstein, 1995; Snijders y Bosker, 1999; Courgeau, 2004]. Otros enfoques han combinado el análisis multinivel y el análisis de redes sociales. Así, Lazega et al. (2007, 2008, 2010), a través de un estudio sobre la élite de los investigadores del cáncer en Francia, proponen un nuevo método para el análisis de dos redes sociales, una inter-individual, la otra inter-organizacional que se conectan con el 
método del linked design (Parcel et al. 1991). Ellos estudian en un principio los diferentes niveles de análisis por separado, y luego articulan estas redes con lazos de afiliación. Esta perspectiva permite de estudiar las relaciones entre posición, estrategia y rendimiento. A la vez, es una manera de mantener esta dualidad entre individuos y organizaciones (Brailly y Lazega, 2012; Lazega, 2012), sus feedbacks, y la dinámica entre encastramiento et desacoplamiento. Este enfoque ha sido utilizado recientemente en la sociología de la ciencia (Bellotti, 2012) y en la sociología económica (Pina-Stranger y Lazega 2011). El enfoque multinivel de Lazega et al. parece ser un marco teórico y metodológico apropiado para capturar este proceso de transición de la relación inter-individual a la relación entre organizaciones en un mercado.

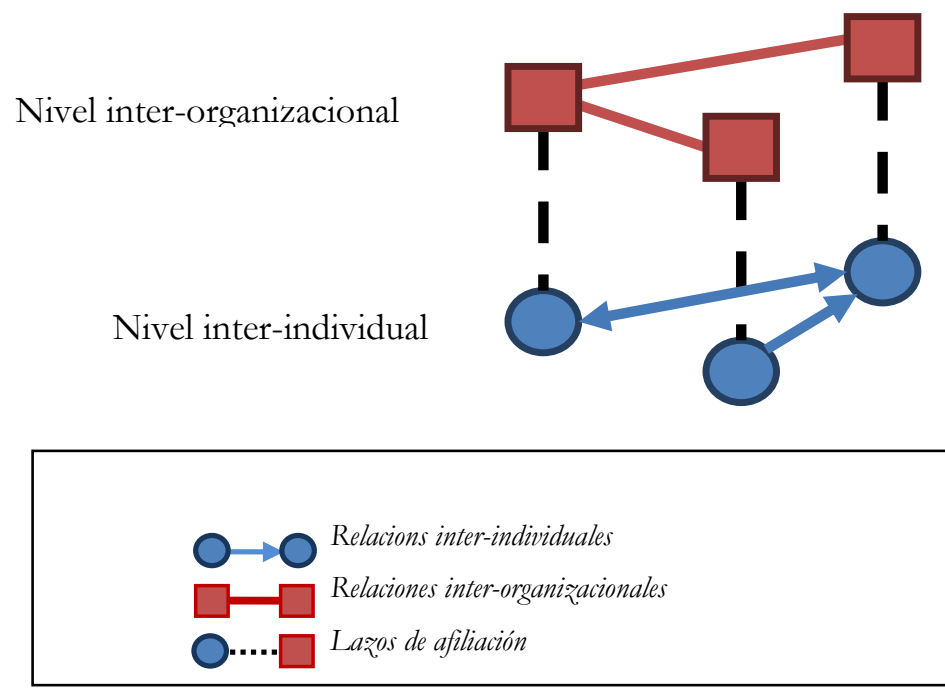

Figura 1: Representación de una red multinivel

Creemos que esta pregunta va en la misma línea que la pregunta de la construcción social de los mercados (García-Parpet 1986, Zelizer, 1983; Bourdieu y Christin, 1990, Fligstein, 200, o Delarre, 2005). De hecho, el encastramiento y el desacoplamiento son procesos dinámicos y constantemente en tensión. Ellos pueden fortalecer o debilitar la autonomía de las organizaciones frente a las relaciones individuales y de manera general, la autonomía de las actividades económicas ante las estructuras sociales. Lorenz (2001) subraya que la confianza entre ambas organizaciones sólo puede pasar a través de los "brokers" quienes transmiten la confianza a los demás miembros de la organización. El establecimiento de colaboraciones repetidas provoca una confianza "inducida" más robusta que un simple conocimiento. Este proceso parece paralelo a lo descrita por Grossetti y Bes. Se podría considerar el proceso de construcción social de los mercados en la perspectiva de Polanyi como un desencastramiento (Polanyi, 1944) - o desacoplamiento en las palabras de White - de la relación comercial de las 
interacciones sociales. Este cambio de contexto podría ser visto como una transición de relaciones inter-individuales a relaciones inter-organizacionales. Establecemos la hipótesis, que para permitir la construcción de un mercado, es necesario establecer relaciones desacoplados entre las empresas, es decir contratos comerciales independientes de las relaciones interpersonales de sus miembros. Según Lorenz (2001), este proceso necesita en un principio, de relaciones interindividuales para crear una base que sustente el contrato, para luego abstraerse de estas una vez que estas relaciones son rutinarias.

Desde este punto de vista, la construcción de un mercado requiere encuentros entre individuos - al menos inicialmente - para fomentar la interacción entre los individuos y ayudar a establecer asociaciones estables entre las dos organizaciones. Las relaciones entre individuos no necesitan ser constantes pero son necesarias para impulsar esta asociación entre organizaciones. Así Rychen y Zimmerman (2008) enfatizan la necesidad de proximidad geográfica temporal en un momento dado para facilitar estos intercambios interpersonales.

Según Bathelt y Schuldt (2008), la nueva economía global se caracteriza por las dificultades para las empresas a identificar nuevos clientes o proveedores de diferentes partes del mundo para construir global pipelines, es decir, los lazos internacionales con otras compañías para diversificar sus recursos (tarea más fácil a nivel local). Estos vínculos pueden facilitar el acceso a nuevos conocimientos y oportunidades y no requieren co-localización constante, pero sólo una proximidad geográfica temporal. Por lo tanto, para estos autores, estos lazos se construyen en los salones internacionales que combinan el microcosmos de la industria en un solo lugar. Además, estos eventos ayudan a desarrollar y difundir los conocimientos sobre la estructura de la cadena de valor y su evolución. Asimismo, estos eventos contribuyen a un proceso de aprendizaje colectivo. Máskell et al. (2005) hablan de "global buzz" para describir este fenómeno. Reuniendo temporalmente en el mismo lugar los actores del mercado, estos eventos son el lugar de construcción de la estructura social del mercado y su endogenización por los individuos (Lazega y Mounier, 2002). En la perspectiva de White, estos lugares permiten a los actores de observar a sus competidores para determinar sus comportamientos (White, 2002).

Estos eventos incluyen no sólo las empresas sino también a sus representantes. Se trata de una reunión entre actores individuales para la creación de alianzas entre organizaciones. Tienen como objetivo promocionar a la empresa que representan y recoger la información pertinente que fluye durante el evento para transmitírsela a su empresa. En este sentido, podemos considerar estos representantes como los "gatekeepers" de las empresas para acceder a las oportunidades económicas y las 
tendencias del mercado. La dimensión multinivel de este sistema social es visible ya que los actores tienen un doble estatus (individual y organizacional).

Proponemos de explorar esta perspectiva multinivel de la construcción social de los mercados del caso del mercado de contenidos audiovisuales en África subsahariana. A través del análisis de un salón donde compradores y vendedores se reúnen para vender y comprar programas de televisión en África, tratamos de comprender la estructura de este mercado a través de un análisis conjunto de redes interindividuales y entre inter-organizacionales.

\section{El caso del mercado audiovisual africano}

Proponemos estudiar un salón internacional de distribución de programas de televisión en África sub-sahariana. Este salón reúne a las diversas partes interesadas con el objetivo común de compra y venta de programas para su difusión en los canales de televisión en África. La cadena de valor del sector audiovisual es relativamente compleja, entre el productor y el espectador hay muchos intermediarios con papeles muy diferentes: productores de contenido, distribuidores de contenidos, teledifusores, fabricantes de satélites, proveedores de capacidad satelitales, operadores de cable, diseñadores y distribuidores de pack de canales,... Sin embargo, para simplificar es posible dividir la cadena de valor en tres etapas claves: la producción de programas, la distribución y la difusión. El salón que estudiemos concierne a la segunda etapa, es decir, la distribución y la adquisición de derechos de difusión de programas.

Así, tenemos por un lado, a los vendedores de programas que puede ser empresas de producción audiovisual, grupos de medios e intermediarios internacionales de distribución. Por otro lado tenemos a los compradores de programas que pueden ser canales de televisión que tratan de completar su parrilla de programación, o intermediarios que compran para revender los derechos de transmisión a nivel local. Por lo tanto este mercado es un mercado de profesionales (un mercado de $B$ to $B$ ): los actores individuales son en su mayoría vendedores de profesión, responsables de la adquisición de los canales de televisión o responsables de la programación. Las relaciones entre compradores y vendedores son altamente personalizadas, estas personas se conocen entre sí y se reúnen periódicamente (o por lo menos lo intentan). Esta etapa de la cadena de valor de la industria audiovisual es una operación clave, ya que define lo que será transmitido en cada país. La economía del sector audiovisual aparece aquí como una forma de intermediación y de prescripción (Hatchuel, 1995; Benghozi \& Paris, 2003). Esta etapa de la cadena de valor impacta y determina el patrón de consumo del cliente final, es decir el espectador. 
El sector de la distribución se caracteriza por la importancia de salones, festivales y conferencias que reunían los actores de la profesión. Estos eventos son muy comunes en los sectores audiovisuales y dan el ritmo de las agendas de los actores. Reúnen a compradores y vendedores de contenido de todo el mundo para conocer a los clientes potenciales y proveedores. Estos eventos son mercados concretos, donde la oferta y la demanda se encuentran cara a cara.

Para comprender el caso de la construcción del mercado de la distribución audiovisual en África, debemos dar algunos elementos históricos. Los canales de televisión africanos aparecen después de la descolonización, época en la cual los gobiernos africanos desarrollan los medios de comunicación nacionales para fortalecer su poder. Hasta principios de los años 90, el panorama de los medios de África se ha caracterizado por el monopolio de los canales públicos cuyo principal programa fue el telediario. Poca atención se le dio al resto de la parrilla programática. La esfera comercial estaba prácticamente ausente de la televisión africana marcada por un papel esencialmente político. El punto de partida del mercado audiovisual en África parece estar dado por la liberalización - en el sentido económico - durante los años 80 de la prensa en varios países de África, y de la radio en los años 90. Así aparecieron poco después los canales privados de televisión. Grupos especializados en los medios de comunicación aprovechan el contexto de desaparición de los monopolios para invertir en la televisión. Hoy, habrían más de 400 canales de televisión privados y públicos en África subsahariana.

Recientemente, el mercado africano ha sido testigo de una explosión de inversiones en los grupos de medios de comunicación locales y extranjeros. En los países más dinámicos (especialmente en el este de África) observamos una explosión de la tecnología digital con el lanzamiento de plataformas de satélite o TNT. Inconcebible hace una década, la idea de la competencia entre las cadenas de televisión comenzó a aparecer. Atraer al espectador se convierte en un aspecto central y en un elemento clave de esta competencia. En esta situación, las cadenas se ven obligadas a invertir en nuevos programas para diversificar su oferta y así captar a la audiencia.

El telediario no puede ser la pieza central de una televisión que deben tratar de completar su parrilla de programación para atraer a los espectadores para cada horario de la parrilla. Hasta ahora, estas cadenas nunca habían hecho adquisiciones de programas y generalmente no tienen servicios de adquisición ni administración publicitaria. Además, la falta de los recursos asignados a la adquisición de contenido, así como el aislamiento de estas cadenas africanas hacía de África un 
continente olvidado de los distribuidores de programas. Lo que marca el mercado audiovisual africano hoy es su falta de recursos financieros. Los auspiciadores son pocos y no permiten crear márgenes económicos significativos para las cadenas. Los fondos públicos - cuando los hay - se utilizan principalmente para las operaciones internas, evitando así ciertas inversiones, como la adquisición de programas. Además, el mercado audiovisual africano sufre de lagunas en la regulación, en particular, en relación con el problema de la piratería.

Hay que subrayar que la situación es muy diferente: en África francófona, es decir, en las antiguas colonias francesas y el Congo, o en el África anglófona. La situación económica que acabamos de describir es principalmente la de la África francófona. El África anglófona sufre el mismo tipo de lagunas, sin embargo, en estas regiones el sector audiovisual empieza a seguir una lógica de producción industrial ${ }^{4}$, y las cadenas están estableciendo administraciones publicitarias y creando fondos para la adquisición de contenidos.

Cabe destacar que los distribuidores internacionales se están interesando crecientemente en el mercado africano. La aparición de nuevos medios de comunicación, el escaneo, y en especial el entorno económico han reducido en gran medida el precio de venta ${ }^{5}$, obligándolos a buscar nuevas oportunidades de ingresos a través de una diversificación geográfica. Es en este contexto se creó el salón DISCOP África cuyo objetivo es reunir a los cadenas de televisión africanas y a los distribuidores de contenidos audiovisuales a nivel internacional. DISCOP acompaña el proceso de mercantilización del sector de la distribución audiovisual en África. Además, la reunión de representantes de las cadenas africanas permite reagrupar una industria previamente fragmentada. Los actores pueden comparar lo que está sucediendo en su país con lo que sucede en otros países.

\section{El salón Discop}

El salón es organizado en un hotel dos veces al año en varias capitales africanas: En Dakar (Senegal) y Nairobi (Kenya) en 2009 y 2010 y en Accra (Ghana) en 2011. El hotel se encuentra generalmente aislado y una parte está reservada exclusivamente para el evento. Las entradas son limitadas a los participantes acreditados, lo que hace que sea un área de mercado relativamente cerrada en la que los participantes están concernidos por el evento. Todos estos actores tienen perfiles diferentes. El organizador del salón agrupa estos participantes en 5 categorías:

\footnotetext{
${ }^{4}$ Sobre todo en Nigeria, donde la producción, simbolizado por el concepto "Nollywood", es de miles de horas de ficción y películas al año.

${ }^{5}$ Debido a la reducción de los inversiones de la publicidad, ingresos mayoría de los cadenas de TV
} 
Los compradores: Esta es la categoría más representada en el salón. Encontramos principalmente directores de adquisición de programas o presidentes de cadenas africanas, distribuidores intermediarios locales que tratan de adquirir los derechos de difusión de programas para redistribuirlos en su país y representantes de grupos internacionales de medios de comunicación que tienen cadenas locales o continentales.

Los Vendedores: Esta categoría comprende en primer lugar proveedores de contenido, es decir, los productores, los intermediarios de distribución o grupos de medios internacionales. Por otro lado, esta categoría considera actores que no participan en la compra y venta de contenidos pero que quieren conocer a los representantes de las cadenas de televisión locales por otras razones: vendedores de frecuencias satelitales, pack de cadenas o grandes cadenas públicas de Información internacionales quienes desean ser difundido en los packs de canales africanos.

Productores: En esta categoría está compuesta de pequeños productores africanos invitados a las conferencias y debates. Tienen stands que les permiten presentar sus productos a los compradores. Podemos considerarlos como "vendedores pequeños".

Visitantes: Otros participantes que no suelen participar directamente en la compra y venta de programas de televisión. Aún así, pueden ser parte de la industria audiovisual, que les da un papel importante en el salón: políticos, embajadas, consultores y periodistas.

Staff: Se trata de los representantes de la empresa organizadora del salón.

Estas categorías representan las personas, no las organizaciones. Aunque en el salón estas funciones son a menudo exclusivas, es posible que una empresa este representada tanto por los vendedores, los compradores y visitantes. Por otro lado, un individuo asimismo puede registrar tanto como vendedor y como comprador al mismo tiempo ${ }^{6}$.

Concretamente, el salón está organizado en varios pisos. Cada piso dispone de varias salas, que están compuestas por stands que son utilizados por los vendedores. Todos estos espacios no son equivalentes. Los vendedores pueden alquilar diferentes tipos de stands, desde la simple mesa adornada del nombre de la empresa a la habitación del hotel completamente cerrado y equipado con varias pantallas que les permite presentar sus programas. Existe una jerarquía entre estas

\footnotetext{
${ }^{6}$ Solo uno de los participantes de la pasada edición fue en este caso.
} 
casetas que puede jugar en varios aspectos: visibilidad, prestigio y funcionalidad. Las empresas también pueden invertir en su visibilidad auspiciando el evento. Pueden proyectar sus programas en las pantallas en todo el hotel, instalar banners, posters, carteles y colocar sus logotipos en las bolsas disponibles a cada participante. Los compradores, circulan en las diferentes casetas para reunirse con los proveedores, consultar los programas en sus catálogos, ver extractos y tomar decisiones de inversión. Además, los participantes registrados como vendedores y / o compradores tienen una plataforma en la página web del evento que les permite consultar la lista de los participantes, organizar y planificar sus agendas de reuniones. Los actores pueden identificar qué tipos de programas (animación, documental, concursos, películas...) son vendidos por quien y proponer una reunión en el salón a través de esta plataforma.

Esta plataforma es muy usada en el salón, debido a que la mayoría de los participantes no se conocen de antemano. Como la utilidad o la eficacia de cada reunión es relativamente incierta para cada uno de estos actores, este servicio puede ser de ayuda para identificar clientes potenciales o proveedores. Sin embargo, las reuniones informales siguen siendo el aspecto más importante en este tipo de eventos. En efecto, si una gran parte de los encuentros se realizan durante reuniones formales, muchos encuentros se efectúan alrededor de conferencias, cócteles y fiestas organizadas al fin de día.

\section{Un análisis de las redes de interdependencia entre los participantes del salón}

De alguna manera el salón DISCOP institucionaliza el mercado de la distribución audiovisual en África. El aislamiento de las cadenas de África y la falta de interés de los distribuidores internacionales para el continente hacía difícil el encuentro entre la oferta y la demanda. Dando un marco concreto y físico al mercado, DISCOP se convierte en un arena de mercado (White, 1992), que pueden formar las primeras alianzas comerciales a través de las relaciones creadas.

En ese lugar, los compradores y vendedores se encuentran en una situación de incertidumbre. De hecho, la mayoría de los proveedores prospectan compradores africanos por primera vez y están claramente descubriendo este mercado. Aunque los salones puede ser una oportunidad para mantener la relación con sus clientes, DISCOP está orientado a los negocios y a la búsqueda de nuevas relaciones. Para aclarar, una gran parte de los vendedores no conocen la situación del mercado 
africano $y$, por tanto, existe una fuerte incertidumbre sobre el reconocimiento de los actores clave, el nivel de precios o el tipo de programas exitosos en esta área ${ }^{7}$.

Además a causa de los problemas inherentes al mercado africano, los vendedores se enfrentan al riesgo de impagos y a la piratería. Lo que está en juego principalmente para los vendedores es identificar oportunidades comerciales y seleccionar socios confiables. Para reducir esta incertidumbre los proveedores debe ser capaces de obtener información precisa sobre actores específicos. Esta información se obtendrá en parte de sus colegas o competidores. De hecho, suelen intercambian información acerca de sus propias experiencias de ventas internacionales. Pero también buscan esta información con los compradores que son los principales expertos en su mercado. Esta informaciones pueden incluir información sobre el tipo de programas que los cadenas buscan, los tipos de derechos específicos buscados, información sobre la persona y su manera de negociar o las condiciones del mercado (países en los que el mercado está creciendo y donde las cadenas empiezan a detener los medios para la adquisición) sobre las parillas de programación, la actividad comercial de los competidores y, a veces los precios de transacción. En definitiva, toda esta información permitirá al vendedor aprovechar las oportunidades de negocios y seleccionar los compradores más confiables para reducir la incertidumbre.

Por otro lado, los compradores se encuentran igualmente en una situación de incertidumbre. Como ya hemos señalado, las cadenas de televisión africanas están relativamente aisladas. EI DISCOP es una manera para que ellas puedan encontrar nuevos distribuidores y diversificar sus fuentes de contenido. Gran parte de su tiempo se dedica a encontrar nuevos proveedores. Por otra parte, una gran parte de los compradores de DISCOP nunca ha visitado un salón antes. EI DISCOP es, pues, el primer y único evento de este tipo en el que participan. Por lo tanto, su objetivo - para adquirir programas externos, por supuesto - es recopilar informaciones sobre el entorno, aprender cómo funciona, lo que se transmite en otros países, modas y tendencias... La adquisición de información sobre el mercado por lo tanto, será una actividad importante de los compradores.

Por lo tanto, los actores se ven obligados a cooperar para protegerse contra los riesgos pero permanecen competidores por posicionarse en el mercado. Este fenómeno es ahora comúnmente llamado "coopetition" (Brandenburger y Nalebuff, 1986). Suponemos una racionalidad social de los actores que son capaces de

\footnotetext{
7 Todos los vendedores no se encuentran en este caso. Algunos son parte de este mercado desde hace varios años y conocen sus condiciones y su funcionamiento. Así, hay diversidad en los motivos de participación para los vendedores en función de su conocimiento del mercado. Entonces hablamos aquí de los vendedores de un punto de vista general.
} 
endogeneizar la estructura relacional y tratar de cambiarla a su favor (Lazega, 2009). En cada salón los actores tratan de adquirir estatus e invierten en nuevas relaciones para moverse dentro de esta estructura y posicionarse en el cruce de flujo de información y de recursos para obtener oportunidades.

Para estudiar a este sistema de interdependencia, hemos realizado una encuesta durante el salón organizado en febrero de 2011 en Accra (Ghana) para recoger datos de redes completas a ambos niveles. Hemos hecho un estudio etnográfico antes del salón (veinte entrevistas). Este estudio ha identificado los recursos sociales que circulan en este tipo de eventos. A continuación, hemos procedido mediante la distribución de cuestionarios sociométricos entre los participantes. El número de participantes es de 300, entonces hemos decidido hacer esta distribución a todos los actores, en vez de hacer una definición de una subpoblación. Dos preguntas sociométricas se propusieron a los encuestados en el cuestionario, una fue para conocer el intercambio informal de información entre los participantes, la segunda concernió contratos entre compradores y vendedores. A partir de las preguntas, presentamos la lista de los participantes a los encuestados. Cada entrevistado debe marcar con una cruz los nombres de las personas con quienes tienen este tipo de relaciones.

La información, como hemos visto anteriormente, es el recurso básico para aquellos actores que están tratando de entrar en un mercado que conocen poco. Sin embargo, esta información puede ser muy diversa y abarca muchas realidades diferentes. Somos conscientes de esta heterogeneidad y multiplicidad de los recursos, sin embargo, preferimos limitar las preguntas sociométricas para limitar el tiempo de llenado y no interferir con la investigación en términos de número de respuestas y de calidad.

Hemos recogido las respuestas de 155 participantes. Las respuestas a la pregunta 1 (solicitaciones por información entre individuales) constituyen nuestro primer nivel, es decir, la red inter-individual. La red puede ser identificada y considerada como el sistema de intercambio informal de los recursos sociales entre los participantes. A partir de la segunda pregunta (contratos entre empresas) se propone reconstruir la estructura económica del mercado y no solo de este salón. De hecho, no se aplica solamente a los contratos firmados durante el salón, sino en todo el año anterior. La firma de los contratos en realidad puede tomar mucho tiempo (a veces más de un año) en el sector audiovisual. Por tanto, es difícil para un vendedor de asignar una venta a un evento en particular. Para él, será luego de muchas conversaciones, discusiones y reuniones que han llevado a un acuerdo. Por lo tanto, reconstruimos una estructura económica más perdurable que la del salón. Aquí el individuo 
responde a la pregunta no solo por él sino por su empresa, la persona no cita a otra persona sino a una empresa. Por lo tanto, se decidió examinar esta relación no como una relación inter-individual, sino como nuestro segundo nivel: la red de transacciones comerciales. Para esto, sumamos todas las citas de empresas (el número de veces que los actores de la empresa citan otra empresa, y el número de veces que su empresa ha sido citada por otros individuos) y binarizamos cada uno de estos vínculos. Este método nos permite tratar el contrato como una relación entre dos empresas. La red cuenta $33 \%$ de relaciones recíprocas, lo cual es relativamente bajo. Decidimos no obstante de simetrizar estos vínculos para gestionar correctamente estos datos. En efecto, el contrato sólo puede ser recíproco por definición. Es posible que algunos actores se hayan negado a revelar ciertos contratos, o simplemente que se hayan olvidado debido a su escasa importancia en términos de valor monetario. También es probable que una persona no sea consciente del contrato si fue hecha por uno de sus colegas.

\section{Una primera mirada en la estructura relacional del salón}

Antes de examinar estas redes simultáneamente en una perspectiva multinivel, debemos entender qué tipo de estructura relacional nos interesa. Presentaremos aquí algunas de las características de la red global formada por el intercambio de información entre los actores individuales, es decir, nuestra red de nivel 1 y los contratos entre empresas. Simplificamos la red por una agrupación de los actores con sus papeles en el salón y con sus originas geográficas. Obtenemos una estructura simplificada de estas dos redes (Fig. 2) que nos permite descifrar rápidamente esta estructura social y económica.

En esta representación de la red, se elimina el grupo "Staff", es decir, el grupo de los organizadores del evento. En efecto, si lo tenemos en cuenta, la red de intercambio de información toma una forma de estrella que hace difícil la lectura. De hecho, estos actores, especialmente dos de ellos, son una fuente esencial de información para los otros actores porque tienen un gran conocimiento del mercado y actúan como intermediarios para introducir a los actores entre sí. No vienen para comprar o vender, sino organizar y estructurar este mercado emergente ${ }^{8}$.

El objetivo aquí no es presentar la red en detalle, sino entender de qué tipo de red hablamos y describir la estructura general. Podemos ver que el intercambio de información (flechas azules) aparecen principalmente entre compradores y vendedores, aquí es donde se encuentra la mayor densidad. Por otra parte, estas relaciones son más o menos recíprocas. En paralelo, los contratos son en su

\footnotetext{
${ }^{8}$ Un estudio de la actividad del "creador de mercado" es uno de los objetivos de investigación futura.
} 
mayoría firmados entre los vendedores y los compradores, aunque hay algunos flujos comerciales entre los vendedores que designan cesiones de derechos para territorios determinados entre los vendedores.

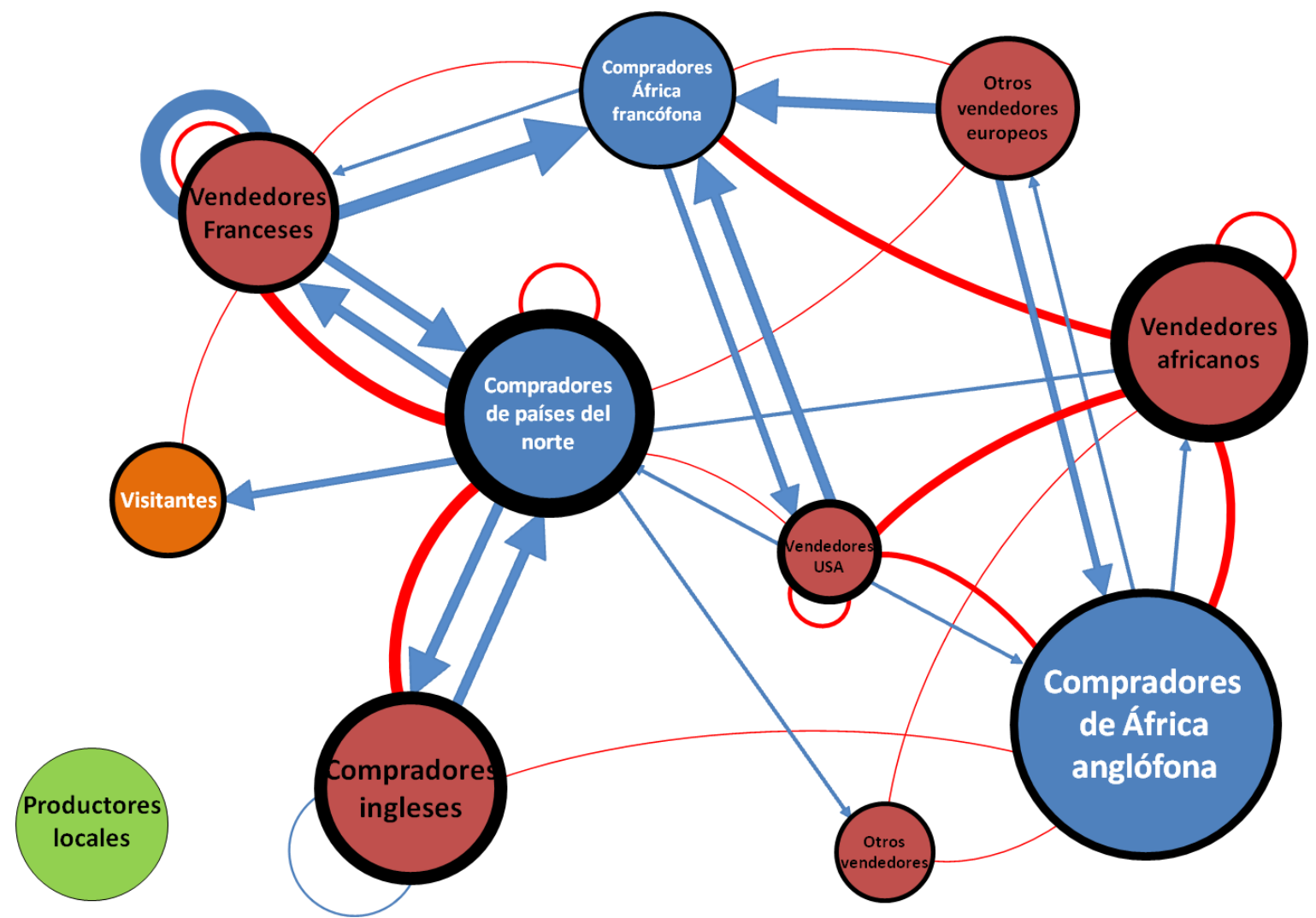

Figura 2: Red simplificada de intercambio de información y de contratos entre los participantes del salón (los actores son agregados con atributos geográficos y de papeles)

Se trata entonces de una estructura de mercado relativamente simple donde los vendedores que deseen explorar nuevos territorios buscan información sobre oportunidades comerciales con las personas directamente afectados por el mercado y por lo tanto más conscientes del contexto local, es decir los compradores africanos que conocen la composición, el nivel de desarrollo y las tendencias en cada uno de sus mercados locales. Sin embargo, todos estos grupos no intercambian información con todo los otros grupos, parece que hay algunas posiciones especiales. Sin entrar en detalles, observamos que existe un medio francófono con una fuerte relación entre vendedores franceses y compradores de África francófona. Los compradores del Norte están a menudo compuestos por cadenas panafricanas, o cadenas europeas dedicadas a la diáspora. Este grupo está compuesto en parte de franceses, lo que explica el fuerte vínculo entre este grupo y los vendedores franceses. Este grupo de compradores del Norte es también el único grupo de compradores en contacto con casi todos los grupos de vendedores, 
mientras que otros compradores están en contacto sólo con algunos grupos particulares. Los compradores del norte son el grupo de los compradores con más dinero para la adquisición.

Subrayamos también el caso de los vendedores africanos que es una excepción: es el único grupo de vendedores que no busca ninguna información (tienen el más bajo score de grado de salida), pero son muy solicitados por otros grupos de compradores. Estos actores están en realidad muy bien establecidos en el mercado africano. Tienen una gran ventaja ya que antes de la reciente liberalización del mercado, se encontraban en una posición cuasi-monopólica. Podemos concluir que estos actores tienen un buen conocimiento del mercado y necesitan muy poca información para mantener su posición. Este grupo es también el grupo que firma más contratos en el mercado, están en relación comercial con las cadenas de televisión locales y algunos grupos de vendedores de quienes compran los derechos para vender los programas al nivel local.

Además, los productores locales aparecen aislados tanto en la red de intercambio de información y en la red de contratos. Estos actores están invitados a las conferencias organizadas al lado del salón. Siguen siendo, sin embargo, para otros actores "pequeños" y están aislados del resto del mercado.

Algunos grupos son altamente cohesivos. El caso de los vendedores franceses es particularmente interesante, ya que tiene más del $23 \%$ de densidad, lo que hace el grupo más cohesivo, lo que significa que muchos vendedores franceses intercambian información con otros franceses. Encontramos este fenómeno en una menor extensión con el grupo de vendedores ingleses que tienen más de $6 \%$ de densidad (la densidad global de la red es de 3\%). Así, hay relaciones dentro de los papeles formales en el salón, es decir, entre vendedores y compradores, pero estos vínculos no son aleatorios y parecen seguir en parte una lógica nacional. Los vendedores buscan información con otros vendedores de un mismo territorio. No podemos hablar del grupo de vendedores y del grupo de compradores, como con un análisis formal del mercado, porque cada grupo tiene una posición específica. Por ejemplo, los compradores de África francófona no intercambian información con las mismas personas que los vendedores africanos anglófonos o vendedores de Norte América. Hay una estructura social que se construye socialmente y se estabilizó temporalmente. Esta estructura también deja aparecer modelos de negocios (business model) específicos: todos los grupos de vendedores no tienen relaciones comerciales con todos los grupos de compradores. Vendedores africanos parecen por ejemplo dirigidos a todos los compradores locales, mientras que otros vendedores se centran principalmente en los compradores del norte. 


\section{Hacia un análisis multinivel}

Esta breve descripción de las dos redes nos da la estructura general del sistema socio-económico. Ahora vamos a focalizarnos en un enfoque diádico, centrándonos en los dos tipos de relaciones estudiadas y su dualidad. Como hemos visto, desde el momento en que se firma un contrato entre dos organizaciones, este vínculo no se puede considerar como una relación entre dos personas, sino que se convierte en un vínculo institucionalizado entre las dos organizaciones. Teniendo en cuenta estas dos redes superpuestas por el linked design que permite tener en cuenta la agregación de dos contextos estructurales. El resultado final es un meta-red multinivel (Brailly y Lazega, 2012; Lazega et al., 2010.). El primer nivel consiste en las relaciones de intercambio de información entre los individuos en el salón. El segundo nivel consiste en los contratos de compra y venta entre las organizaciones. Estos dos niveles están conectados por los lazos de afiliación de los individuos a las organizaciones.

Para aproximarse a la estructura de esta meta-red, hemos decidido centrarnos en las sub-estructuras relacionales formados por las relaciones entre individuos y entre organizaciones. Este enfoque proporciona un medio para entender la construcción de la red y capturar a los procesos de formación de varios niveles. Holland y Leinhardt (1976) hacen hincapié en la importancia del análisis de sub-estructuras relacionales para comprender la estructura general de las redes sociales. Han identificado sub-estructuras tríadicas en redes de sentimientos y han desarrollado un índice estadístico que mide la desviación con respecto a un modelo aleatorio. El análisis de cada tipo de triada permite entender cómo se estructura una red social global y introduce un análisis de la transitividad en las redes sociales. Tomamos este enfoque aquí en parte para no centrarnos en las sub-estructuras tríadicas, sino en las sub-estructuras tetrádicas formadas por las redes inter-individuales e interorganizacionales.

Retomamos las sub-estructuras multinivel generadas por Brailly y Lazega (2012). Estos han distinguido 10 sub-estructuras multinivel basadas en la ausencia, presencia y orientación de los vínculos que aparecen en cada nivel. En nuestro caso, el primer nivel se compone de relaciones orientadas (solicitaciones de información), pero el nivel 2 tiene vínculos simétricos (contratos de compra y venta de programas). Entonces conservamos cinco sub-estructuras. 
Nivel inter-organizacional

Nivel inter-individual

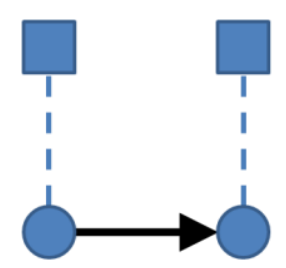

MS 2

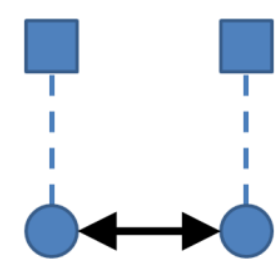

MS 3

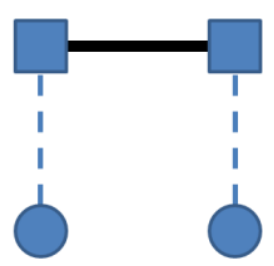

MS 4

Nivel inter-organizacional

Nivel inter-individual

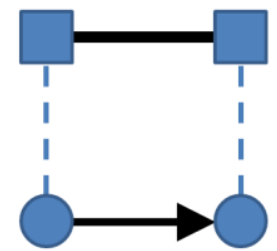

MS 6

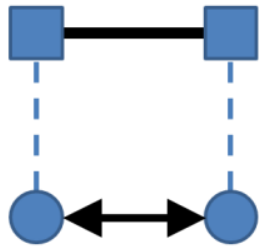

MS 9

Figura 3 : Cinco sub-estructuras multinivel (Brailly \& Lazega 2012) que tomamos por la análisis

Cabe señalar que para este análisis tomamos solo en cuenta las sub-estructuras compuestas de actores con el papel de comprador o vendedor. De hecho, los visitantes y el staff no compran ni venden. En paralelo, los productores locales contratan muy poco. Esto se refleja en la ausencia de vínculos al segundo nivel, y por lo tanto provoca sobre-representados sub-estructuras con ninguna relación entre las organizaciones. De hecho, sólo se consideran las sub-estructuras formadas por los actores con el papel de vendedores o compradores.

En primer lugar describimos cada sub-estructura y las interpretaciones que podemos hacer de esta. En nuestro caso el segundo nivel refleja una estructura de mercado, la relación entre los niveles es fuerte, ya que en gran parte es debido a las actividades de los actores individuales. Estos actores son comerciales profesionales, y construyen en gran parte el segundo nivel por su actividad. Diseñamos estas sub-estructuras más bien como un proceso de construcción de abajo hacia arriba.

MS2: Vínculo individual orientado

Las organizaciones no están conectadas, pero hay un vínculo dirigido entre individuos. Esto puede reflejar una solicitud unilateral de información. En nuestro 
caso, la sub-estructura puede reflejar una simple búsqueda de información rápida, una prospección sin compromiso entre las organizaciones.

MS3: Vínculo Individual recíproco

Las organizaciones no están conectadas, pero existe una relación recíproca entre individuos. El vínculo entre los individuos sería independiente de las empresas. Esto refleja un intercambio recíproco de información entre individuos sin que se traduzca por un contrato. También es posible que se trate de un intercambio de información entre los empleados de empresas más o menos similares, en competición o en nichos muy diferentes, lo que explica la ausencia de contrato.

Estas dos primeras sub-estructuras se refieren a casos donde la red inter-individual es completamente independiente de la red inter-organizacional. Así pues, podemos considerar que estas sub-estructuras son indicativas de una acción de prospección de los actores, un descubrimiento del mercado o de un posicionamiento relacional para iniciar negociaciones.

\section{MS4: Vínculo organizacional}

Los individuos no están conectados pero existe un vínculo entre las organizaciones. Esto significa que existe una relación entre organizaciones independiente de un vínculo individual. En nuestro caso, el contrato puede ser firmado antes del salón, las empresas han tenido la oportunidad de encontrarse en otro contexto. También es posible que una negociación rápidamente llegara a conclusión sin que un intercambio real de información fuera necesario. El contrato habría concluido sin interacción profunda entre los individuos. Esta situación es indicativa de un desacoplamiento porque la asociación de las organizaciones no sería la consecuencia de la acción de los representantes en el salón, sino del conjunto de la empresa.

MS6: Vínculo individual orientado y vínculo organizacional

Existe un vínculo orientado entre los individuos y un vínculo al nivel de las organizaciones. Esta estructura podría deberse al hecho de que la relación interpersonal proviene principalmente de una persona (el receptor de la relación), quien tendría un gran conocimiento del mercado. El vínculo inter-organizacional esta encastrado en la red de - al menos - uno de los individuos.

MS9: reciprocidad individual y vínculo organizacional

Las relaciones entre los individuos y entre las organizaciones son recíprocas. Es una situación de encastramiento con relaciones bilaterales entre los actores. El contrato 
entre las organizaciones se debe enteramente a la relación de los dos individuos. Se conocen, intercambian informaciones y así inician el contrato.

Estas dos últimas estructuras reflejan el proceso de encastramiento. La relación contractual entre las empresas se inicia al nivel individual y parece ser dependiente.

Tratamos de identificar cada una de estas sub-estructuras en la red multinivel. El objetivo por ahora es sólo contar cuántas veces aparece cada una de estas subestructuras ${ }^{9}$.

\begin{tabular}{|c|c|}
\hline Subestructura & Número censado \\
\hline MS2 & 462 \\
MS3 & 55 \\
MS4 & 213 \\
MS6 & 154 \\
MS9 & 38 \\
\hline Total & 922 \\
\hline
\end{tabular}

Figura 4: Censo de todos los tipos de sub-estructuras tetrádicas en la red multinivel del salón

Observamos que las estructuras menos densas aparecen a menudo, es decir las estructuras 2 y 4, que se componen de vínculos en un solo nivel. Las subestructuras recíprocas, es decir 3 y 9 son menos frecuentes. Estos resultados dan pequeños elementos para el análisis cuando son estudiados solos. Nuestro objetivo es entender las características de estas sub-estructuras y entender las condiciones de su emergencia.

Para entender la composición de estas estructuras, los caracterizamos con diversas variables tetrádicas. Cada sub-estructura se compone de cuatro actores: dos individuos y dos organizaciones. De este modo podemos caracterizarlos por los atributos de cada uno de estos cuatro actores. Hablamos aquí de variables de interacción. Al final, mantenemos seis variables de interacción que representan 20 modalidades. ${ }^{10}$

- La frecuencia de la presencia de los actores en el salón: El actor es "habitué" si participaba más de dos veces a las ediciones anteriores del salón, es "novice" en el caso contrario. Entonces, la variable de interacción tiene tres modalidades:

\footnotetext{
${ }^{9}$ Sub-estructuras sin vínculo ni al nivel de los individuos ni al nivel de las organizaciones fueron excluidas del análisis.

${ }^{10} \mathrm{El}$ análisis se realiza en francés, los nombres de las variables no las hemos traducido, por esta razón utilizamos nombres en francés en esta parte
} 


\section{habitué/habitué}

○

\section{habitué/novice}

○ novice/novice

- El papel de los actores en el salón: Puede ser un "acheteur" (comprador) o "vendeur" (vendedor). La variable de interacción puede adoptar tres formas:

- acheteur/acheteur

$\circ$ acheteur/vendeur

- vendeur/vendeur

- Homofília o heterofília de país de origen de la empresa: Si dos empresas son de un mismo país, la sub-estructura se considera como homófila, a lo contrario se considera como heterofíla. La variable de interacción tiene dos formas:

\section{○ Homophile_pays \\ ○ Hétérophile_pays.}

- El nivel de prestigio de los actores individuales: Utilizamos aquí la terminología de los poissons (peces) y mares (estanques) de Lazega et al. $(2007$; 2008) para caracterizar el doble posicionamiento de un individuo en una estructura multinivel. En nuestro caso, si una persona tiene un score de grado interior ${ }^{11}$ más alto que el grado interior medio de la red inter-individual, se considera como un grand poisson (GP o gran pez), a lo contrario se considera como un petit poisson (PP o pez pequeño). Esto nos da tres formas para caracterizar una sub-estructura con este criterio:

- GPGP : Si concierne únicamente a grand poissons

- PPPP : Si concierne únicamente a petits poissons

- GPPP : Si concierne a un petit poisson y un grand poisson

- El nivel de prestigio de las organizaciones: De la misma manera, si una organización tiene un grado más alto que el grado medio de la red interorganizacional, se considera un grande mare (GM o gran estanque) en el caso contrario, se considera un petite mare (PM o pequeño estanque). Esto nos da tres formas para caracterizar una sub-estructura con este criterio:

GMGM : Si conierne únicamente a grandes mares

○

$$
\text { PMPM : Si concierne únicamente a petites mares }
$$

\footnotetext{
${ }^{11}$ El grado interior es igual al número de vínculos dirigidos a este actor, es decir, el número de veces que un actor es citado por los otros. Podemos considerarla como una medida del prestigio de un actor.
} 
- La frecuencia de presencia de los actores en el territorio africano: Algunos actores viven en el territorio africano (la modalidad descrita aquí AFRIQUE). Algunos están familiarizados con el continente y han estado presentes más de dos veces durante el año (que se describe aquí por la modalidad SOUVENT que se traduce por "a menudo") mientras que los otros que están menos acostumbrados si han estado presentes menos de dos veces en el continente (RAREMENT que se traduce por "rara vez"). La variable de interacción tiene cinco modalidades:

- Afrique/Afrique

- Afrique/Souvent

- Afrique/Rarement

- Souvent/Souvent

- Souvent/Rarement

- Rarement/Rarement

El objetivo aquí es de caracterizar a las sub-estructuras identificadas mediante estas variables de interacción para revelar los procesos locales sociales que subyacen a la aparición de estas sub-estructuras. Caracterizar estas subestructuras permite entender quienes de los actores tienden a tener relaciones de intercambio de información y relaciones económicas encastradas o desacopladas. La descripción de estas características permite una aproximación de la causalidad de estos procesos. Realizamos un análisis de correspondencia múltiple (ACM) para describir las sub-estructuras con todos estos atributos. Para comprender las tablas estadísticas sobre las cual trabajamos, el contenido de cada línea representa una sub-estructura identificada. Cada una de las columnas representa los atributos de las organizaciones y de los individuos que conforman estas sub-estructuras. Los ejes del ACM están determinados a partir de estas variables de interacción.

Los tres primeros factores del ACM nos permite explicar casi $30 \%$ de la inercia. Mantenemos estos tres factores principales para el análisis. A continuación, ponemos sobre estos tres ejes identificados por el análisis factorial las diferentes sub-estructuras multinivel como variables adicionales. Esto nos permite comprender los atributos que caracterizan a estas sub-estructuras y lo que los distingue. 
Los dos primeros ejes destacan dos dimensiones. Las variables que participan a la construcción del primer eje son la homofília de países y los modalidades SOUVENT/SOUVENT, SELLER/SELLER, SOUVENT/RAREMENT y HABITUE/HABITUE. Estos modalidades que tiran el eje a la derecha tienen en común de concernir díadas multinivel homofílas de país, interacciones entre actores externos de África (actores que visitan con frecuencia o rara vez en África, pero no viven allí) y entre habitués del salón. También se compone en gran parte de interacciones homofílas entre vendedores y actores prestigiosos (pez grande). Así, algunas díadas son únicamente interacciones entre vendedores internacionales que viniendo a menudo a África, que han participando a menudo en el salón, y que parecen ser importantes en la red de intercambio de información. Este primer eje parece polarizar las díadas entre actores extranjeros y habitués con otras díadas entre locales o diadas entre proveedores internacionales y locales. Así, podemos hablar del eje Geografía / iniciación. Entre más díadas se encuentran a la derecha del eje, más están concernidas las interacciones homofílas entre actores del norte y habitués del salón. En contraste, entre más las díadas se encuentran a la izquierda más estarán compuestas de interacciones que conciernen actores africanos no habitués del salón. 


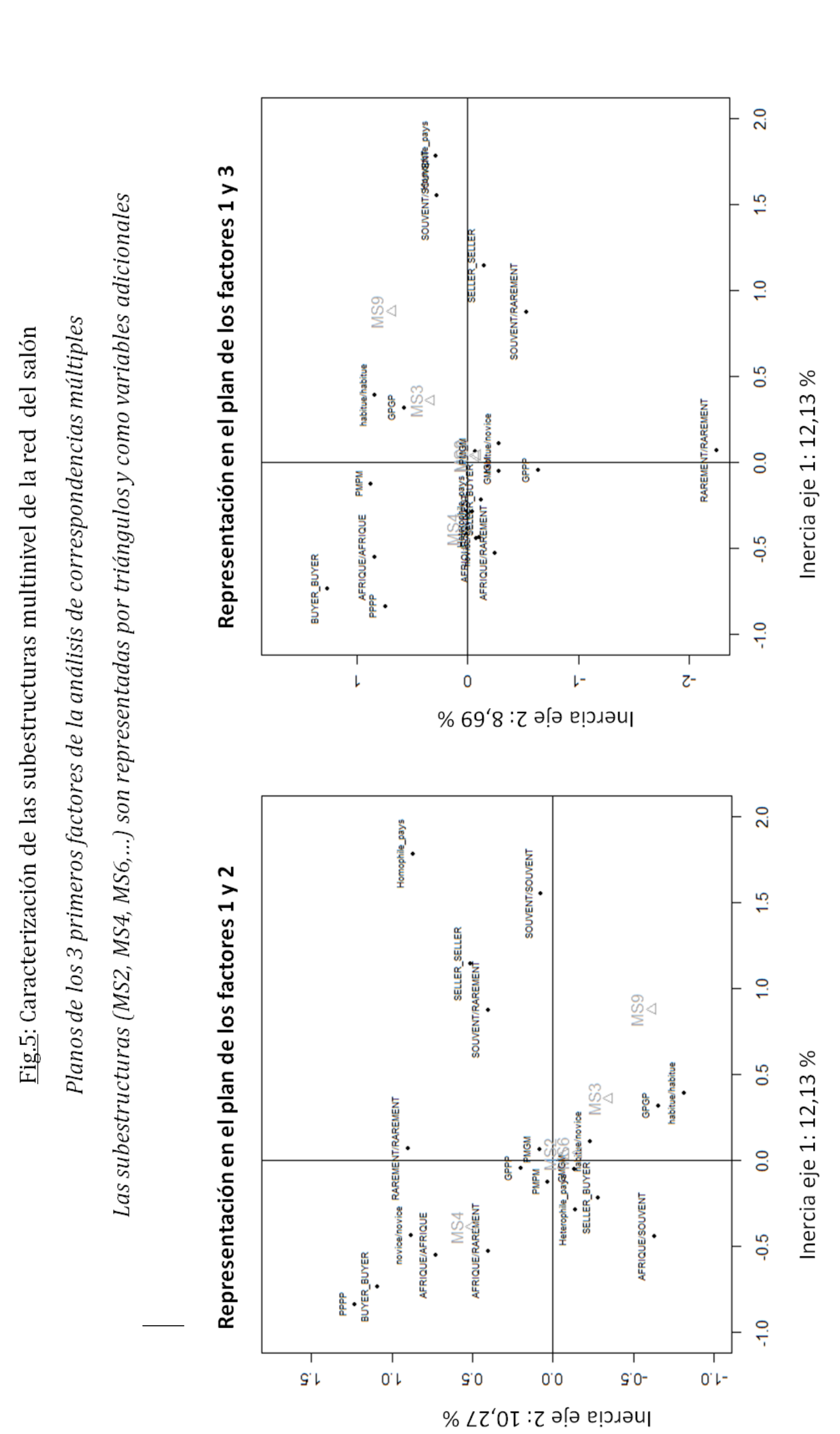


También se puede señalar que los dos modalidades habitué/habitué (acostumbrado) y GPGP (gran pez) están muy cerca de este eje. Estas dos variables son de hecho correlacionadas, entre más un actor participa con frecuencia al salón, más obtiene información de los otros participantes.

Estos dos primeros factores no parecen discriminar MS2 y MS6 que se encuentran en medio de los ejes. Estas sub-estructuras representan formas de exploración del mercado por los actores que se traducían por un contrato en el caso de MS6. Interpretamos estas sub-estructuras como las formas más comunes en un mercado en construcción: la búsqueda de información y la prospección.

Al contrario las sub-estructuras MS3, MS4 y MS9 se distinguen mucho más claramente. MS9 y MS3 se colocan a la derecha del primer eje y al abajo del segundo. Estas sub-estructuras designan principalmente las interacciones comerciales, es decir, las interacciones entre compradores y vendedores y entre los actores que vienen con frecuencia al salón. Por otra parte, designan interacciones entre actores exteriores de África. MS3 y MS9 son, de hecho, las únicas dos subestructuras recíprocas (con la excepción de MS4 que tiene un vínculo simétrico). Podemos concluir que la reciprocidad en el intercambio de información aumenta con el estatus social de estos actores. Ahora bien, entre más un actor participa al salón, más es reconocido por sus colegas como detentando información estratégica sobre el mercado. Se considera, pues, como un "consejero" por los otros, lo que parece favorecer por allí su acceso a otros recursos sociales. MS9 concierne en $37 \%$ de los casos de interacciones homofílas de país de origen de las empresas y MS3 en $20 \%$ de los casos. Los actores por lo tanto, parecen tener intercambios recíprocos de información cuando sus empresas son de un mismo país. Además, es interesante observar que MS9, que caracteriza la sub-estructura con relaciones entre organizaciones más encastradas en las relaciones inter-individuales, se encuentran entre los actores habitués de Discop África. Entre más los actores participan al salón, más tienden a intercambiar información y firmar contratos entre ellos. Así, podemos suponer que la sub-estructura MS3 es un paso previo a MS9 y tenderá hacia la creación de un vínculo entre las dos organizaciones.

La hipótesis de la evolución de las relaciones inter-individuales en relaciones interorganizacionales parece estar confirmada aquí. Sin embargo, MS4 parece caracterizarse más bien por interacciones entre "novice", es decir, interacciones entre individuos que participan al salón por la primera vez, entre "pequeños peces", y entre actores con el mismo papel en el salón (entre compradores o entre vendedores). Pero a diferencia de MS9 que corresponde a una sub-estructura 
totalmente encastrada con vínculos a cada nivel, MS4 es una sub-estructura desacoplada. Existe un contrato entre las dos organizaciones, pero no hay relación entre los individuos. Este resultado es sorprendente, porque podríamos imaginar que relaciones frecuentes entre dos individuos sean necesarias para hacer aparecer este tipo de sub-estructura, que una participación frecuente al salón debe permitir una rutinización de este contrato que no necesita más relaciones inter-individuales. Esperábamos que está sub-estructura aparezca a la derecha y al abajo de los dos primeros ejes de la ACM. Pero es el resultado opuesto que aparece: Entre menos los actores participan al salón, más la relación se desacopla. Hay tres posibles explicaciones para este fenómeno. Algunos contratos se han firmado entre las dos organizaciones fuera del salón y de manera independiente de los individuos que participan al salón. En otros casos, hay algunos actores descubriendo este mercado que tienen una estrategia de posicionamiento en el mercado para adelantarse a sus competidores rápidamente: es la estrategia del "sell and run" ${ }^{12}$. En efecto, hemos visto en el salón que algunos actores que deseen obtener rápidamente un beneficio, tratan de concluir una transacción durante las primeras reuniones con los compradores. El razonamiento es el siguiente: sabiendo que los compradores tienen medios muy bajos para la adquisición de programas, es necesario concluir las transacciones desde el inicio del salón para obtener el porcentaje máximo de su presupuesto antes que sea recuperado por otros vendedores. Otros aceptan dar programas gratuitos para que las cadenas vuelvan a ellos una vez que tienen un presupuesto para adquisiciones. Esta sub-estructura no siempre significa un proceso de desacoplamiento de la relación entre dos personas, sino una estrategia de posicionamiento en el mercado. Finalmente, es también probable que las organizaciones que forman la sub-estructura están representados por varios individuos que representan papeles diferentes (compradores y vendedores), y solo alguno de entre ellos intercambian información. Esto explicaría la posición de la sub-estructura en la parte superior del eje "comercial": Empresas representadas por varias personas están en una relación contractual sin que todos los representantes de estas empresas intercambian información.

El tercer eje no nos da información crucial para la interpretación, sin embargo, parece polarizar las interacciones que involucran a los actores que rara vez van a África con todas las otras modalidades. Podemos interpretar este eje como un indicador de la distinción entre los interacciones con actores quienes tienen intereses en el continente de las interacciones con aquellos actores quien solo prospectan este mercado. Una vez más, MS2, MS6 no se distinguen de manera

\footnotetext{
${ }^{12}$ Expresión utilizada por algunos participantes en las entrevistas
} 
significativa. Sólo MS3 y MS9 se colocan en la parte superior del eje, lo que indica que estas sub-estructuras compuestas de intercambios recíprocos de información se puede encontrar con actores que tienen intereses en el mercado, que viven en África o que van regularmente en África.

\section{Conclusión}

Utilizando al concepto (no la teoría) del encastramiento de Polanyi (1944), adaptado por Granovetter (1984), podemos considerar la construcción de un mercado como un proceso de desencastramiento, que en la terminología de White (1992) podría dar lugar a un proceso de desacoplamiento. Hemos así establecido la hipótesis que la construcción social del mercado seria en primer lugar un proceso de encastramiento de las interacciones comerciales en las relaciones sociales, para luego entrar en un proceso de desacoplamiento entre las relaciones comerciales y sociales. Sin embargo, según nuestras observaciones, vemos bien lo que predecía la sociología económica de White, a saber, un proceso más dinámico, estratégico y complejo. En la medida en que un actor participa más frecuentemente en el salón, sus relaciones económicas estarán acompañadas más frecuentemente de relaciones sociales entre los individuos. Esto nos lleva a pensar que, en una perspectiva dinámica, un mercado tendería a encastrarse en las relaciones individuales más que desacoplarse. Sin embargo, estamos estudiando un mercado en que las relaciones interpersonales son muy importantes. El papel de los responsables de ventas, de programación o de adquisición es clave para la construcción del mercado. Los encuentros personales y repetidos entre estos actores son necesarios. Es evidente que todos los mercados no están encastrados de la misma manera en las redes sociales. Dependiendo de la naturaleza de los bienes intercambiados y el grado de sofisticación de los dispositivos de intermediación, estos mercados pueden ser más o menos independientes de las redes sociales (Grossetti y Bes, 2001). Sin embargo, podemos concluir que en un mercado conocido como $B$ to $B$ (Business to business) el proceso de encastramiento del mercado sigue siendo central. Pero esto el encastramiento también se debe a la inmadurez relativa del mercado de programas audiovisuales en África que requieren encuentros inter-individuales para prevenir de los riesgos de los contratos. Estas reuniones cara a cara son necesarias para el establecimiento de la confianza para la contratación. Por lo tanto, es probable que el proceso observado sea sólo preliminar a una forma de descoplamiento. Sería necesario entonces observar este proceso de manera dinámica. 
Es difícil tener en cuenta tanto la estructura social y económica de los mercados en el análisis de redes sociales. El enfoque multinivel de Lazega et al. (2007, 2008, 2010) para tener en cuenta dos niveles de interacción, parece capturar la estructura económica al considerarla como un segundo nivel. A lo largo de este artículo hemos querido mantener esta dicotomía entre individuos y organizaciones. Los procesos de encastramiento y desacomplamiento son dinámicos y entonces difíciles de capturar en nuestro caso. De hecho, en nuestro mercado, es difícil asignar un contrato a la organización porque vendedores y compradores son profesionales y están al origen de la transacción. Están en la iniciativa del contrato y son a menudo los únicos dos representantes de las organizaciones quienes se encuentran personalmente.

Así, para realmente comprender el efecto estructural de un nivel sobre el otro, creemos que es necesario de estudiar un sistema de interdependencia más variado que una estructura de transacciones al segundo nivel. Relaciones de cooperación, como coproducciones, joint-ventures, coadquisiciones nos parecen necesarias para evaluar el posicionamiento dual y multinivel de un individuo (Lazega et al., 2007) o la red potencial por un individuo que puede ser la red de su organización (Lazega et al. 2010).

El enfoque presentado en este artículo es sólo una primera etapa en el análisis. De hecho, estos resultados deben ser complementados por un análisis que considera simultáneamente diferentes dependencias estructurales dentro los niveles como entre los niveles (Brailly y Lazega, 2012; Lazega, 2012) como lo permite la modelización ERGM-multinivel en desarrollo (Wang, Robins, Lazega \& Pattison, 2012). Estos modelos permiten plantear la cuestión de la temporalidad y de la causalidad entre los diferentes niveles.

\section{Bibliografía}

Bathelt H., Schuldt N. (2008). « Between Luminaires and Meat Grinders: International Trade Fairs as Temporary Clusters », Regional Studies, Vol. 42-6, pp.853-868.

Benghozi P.J., Paris T. (2003). « De l'intermédiation à la prescription : le cas de la télévision », Revue française de gestion, Vol. 142-1, pp.205-227.

Bourdieu P., Christin R. (1990). «La construction du marché », Actes de la recherche en sciences sociales, Vol.81-82, pp.65-85.

Brailly J., Lazega E. (2012). "Diversité des approches de la modélisation multiniveaux en analyses de réseaux sociaux et organisationnels" - Mathématiques et Sciences Sociales, 198(2), pp. 5-32. 
Breiger R.L. (1974). "The duality of persons and groups", Social forces, Vol.53, pp.181-190.

Bryk A.S., Raudenbush S. (1992). Hierarchical linear models, Newbury Park (CA), Sage.

Courgeau D. (2004). Du groupe à I'Individu: Synthèse multiniveau, Paris, Éditions de I'INED.

Delarre S. (2005). «La reproduction des groupes d'entreprises comme entités socio-économiques stables », Revue française de sociologie, vol. 46, n० 1, pp. 115150.

Crozier M., Friedberg E. (1977). L'acteur et le système. Paris, Seuil.

Fligstein N. (2001). «Le mythe du marché », Actes de la recherche en sciences sociales, Vol.139, pp.3-12.

Friedberg E. (1997). Le pouvoir et la règle. Dynamiques de l'action organisée, Paris, Seuil.

Garcia-Parpet M.F. (1986). «La construction sociale d'un marché parfait. Le marché au cadran de Fontaines-en-Sologne », Actes de la recherche en Sciences sociales, Vol.65, pp.1-13.

Goldstein H. (1995). Multilevel Statistical Models, London, Edward Arnold.

Granovetter M. (1985). « Economic action and social structure: the problem of embeddedness ? », American journal of sociology, Vol. 91-3, pp.481-510.

Grossetti M., Bes M.P. (2001). «Encastrements et découplages dans les relations science-industrie. » Revue française de sociologie, Vol. 42, pp. 327-355.

Hatchuel A. (1995). « Les marchés à prescripteurs », in Jacob A. \& Warin H. (Eds.) L'inscription sociale du marché, Paris, L'Harmattan, pp.203-224.

Holland P.W., Leinhardt S. (1976). «Local Structure in Social Networks », Sociological Methodology, Vol.7, pp.1-45.

Lazega E. (2012). « Sociologie néo-structurale », in Razmig Keucheyan \& Gérald Bronner (eds), Introduction à la théorie sociale contemporaine, Paris, Presses Universitaires de France.

Lazega E. (2009). «Théorie de la coopération entre concurrents : organisations, marchés et analyse de réseaux », in Steiner Philippe \& Vatin François (Eds.), Traité de sociologie économique, PUF, Paris. 
Lazega E., Jourda M.T., Mounier L., Stofer R. (2007). « Des poissons et des mares : I'analyse de réseaux multi-niveaux », Revue française de sociologie, Vol.48-1, pp.93-131.

Lazega E., Mounier L. (2002). « Interdependent entrepreneurs and the social discipline of their cooperation: The research program of structural economic sociology for a society of organizations », in Favereau O. \& Lazega E. (Eds.), Conventions and Structures in Economic Organization: Markets, Networks, and Hierarchies, Cheltenham, Edward Elgar Publishing, pp.147-199.

Lazega E.I, Mounier L., Jourda M.T., Stofer Rafaël (2008). « Catching up with big fish in the big pond? Multi-level network analysis through linked design », Social Networks, Vol.30, pp.157-176.

Lazega E., Jourda M.T., Mounier L. (2010). « Network parachutes from tetradic substructures: "Organizational expansion" and the measurement of the contribution of laboratories to their scientists' relational capital and performance », $1^{\text {ère }}$ Journée d'études de l'Observatoire des Réseaux Intra et Inter-Organisationnels (ORIO), Université Paris-Dauphine, 20 Septembre.

Lorenz E. (2001). « Confiance interorganisationnelle, intermédiaires et communautés de pratique », Réseaux, Vol. 108-3, pp.63-85.

Máskell P., Bathelt H., Malmberg A. (2005). « Building Global Knowledge Pipelines: The Role of Temporary Clusters », DRUID Working Paper, N 05-20.

Nalebuff B., Brandenburger A. (1996). La co-opétition, une révolution dans la manière de jouer concurrence et coopération, Village mondial, Paris.

Parcel T.L., Kaufman R.L., Leeann Jolly (1991). « Going up the ladder: multiplicity sampling to create linked macro-to-micro organizational samples », in Marsden Peter (ed.), Sociological methodology, 21, Oxford, Basil Blackwell, pp. 43-79.

Pina-Stranger A., Lazega E. (2011). «Bringing personalized ties back in: Their Added Value for Biotech Entrepreneurs and Venture Capitalists Interorganizational Networks ». Sociological Quarterly, Vol. 52, pp.268-292.

Polanyi K. (1983 [1944]). La grande transformation. Aux origines politiques et économiques de notre temps, Paris, Gallimard.

Rychen F., Zimmerman J.B. (2008). « Clusters in the Global Knowledge-based Economy: Knowledge Gatekeepers and Temporary Proximity », Regional Studies, Vol.42-6, pp.767-776.

Snijders T.A.B., Bosker R.J. (1999). Multilevel analysis: An introduction to basic and advanced multilevel modeling, London, Sage Publications. 
Snijders T.A.B., Baerveldt C. (2003). "A multilevel network study of the effects of delinquent behaviour on friendship evolution", Journal of Mathematical Sociology, Vol.27, pp.123-151.

Swedberg R. (1997). «Vers une nouvelle sociologie économique: bilan et perspective », Cahiers internationaux de sociologie, «Sociologies économiques », Vol..103, pp.237-263.

Van Duijn M.A.J., Van Busschbach J.T., Snijders T.A.B. (1999). « Multilevel analysis of personal networks as dependent variables », Social Networks, Vol. 21, pp.187209.

Wang P., Robins G., Lazega E. \& Pattison P. (2012). « Exponential Random Graph Models for Multi-level networks: Case studies », Multilevel social networks symposium conference, Manchester, 19th - 20th June, The Lowry.

Wang P., Sharpe K., Robins G., Pattison P. (2009). « Exponential random graph (p*) models for affiliation networks », Social Network, Vol. 31, pp.12-25.

White H.C. (1981). « Where do markets come from ? », American Journal of Sociology, Vol.87, pp.517-547.

White H.C. (1992). Identity and Control : A structural theory of action, Princeton, Princeton University press.

White H.C. (2002). Markets from Networks: Socioeconomic Models of Production, Princeton and Oxford, Princeton University Press. 


\section{Anexos}

\section{Preguntas sociométricas utilizadas durante las entrevistas}

1- Trade fairs such as $\mathrm{xxx}$ are good ways to get informal information concerning competitors, suppliers, clients, which programs are successful or trends in the market during discussions or meetings. Among the people in the following list, from whom did you obtain this kind of advice or information during or before xxx? (Could you please check their names in the "advice/information" column?)

Examples of advice: Is this buyer reliable? How should I negotiate with bim? What do you think about the programs of this company?, I think you should have this kind of programs in your catalogue, I think you should broadcast this kind of program during your primetime, it's very successful in my country...

2- Among the people in the following list, with whom did you make a deal in 2010? (Could you please check their names in the "deal" column?)

Porcentaje de explicación de la inercia por factor de la ACM

\section{Eboulis des valeurs propres en $\%$}

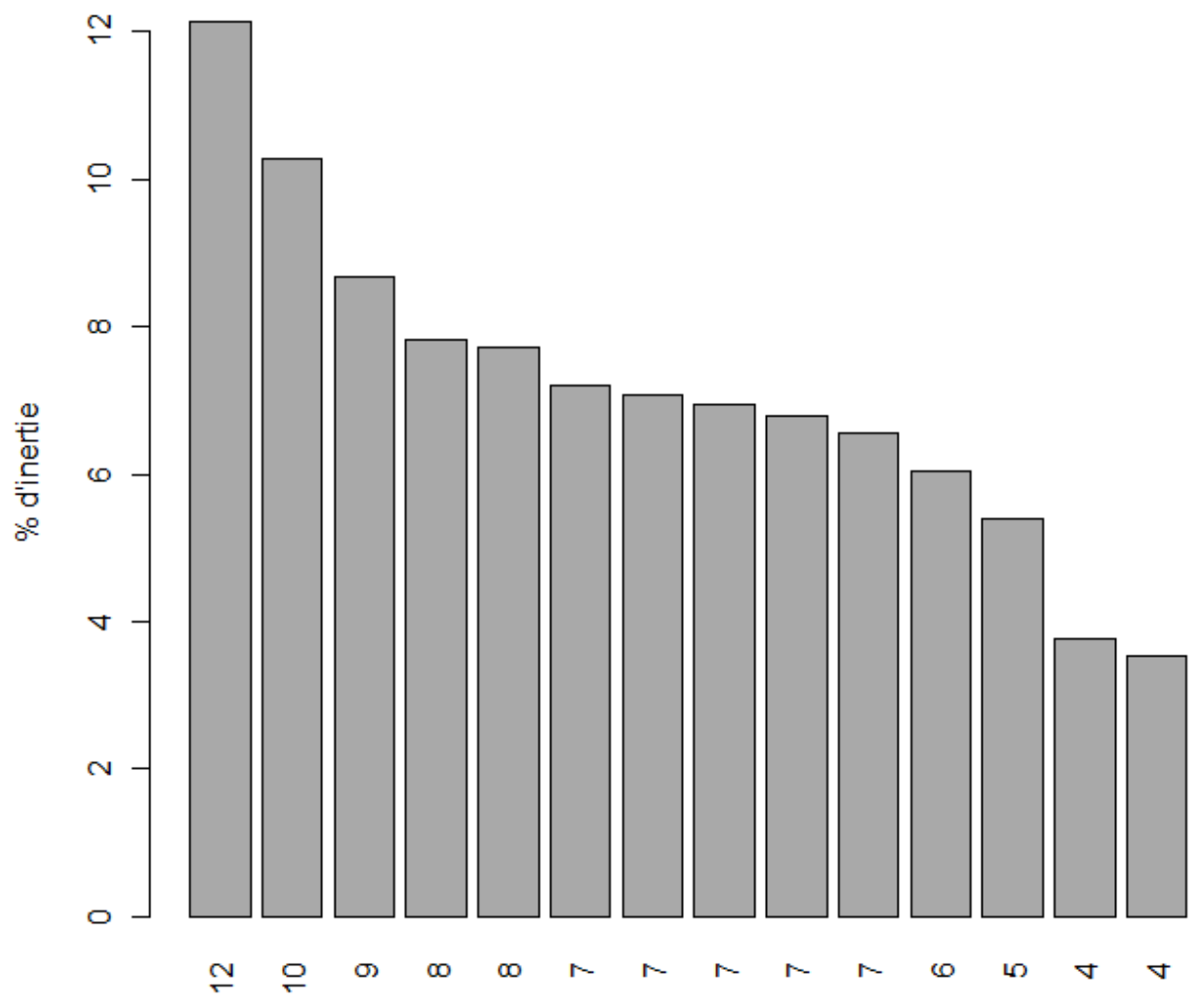


Representación de las sub-estructuras multinivel en los ejes de la ACM

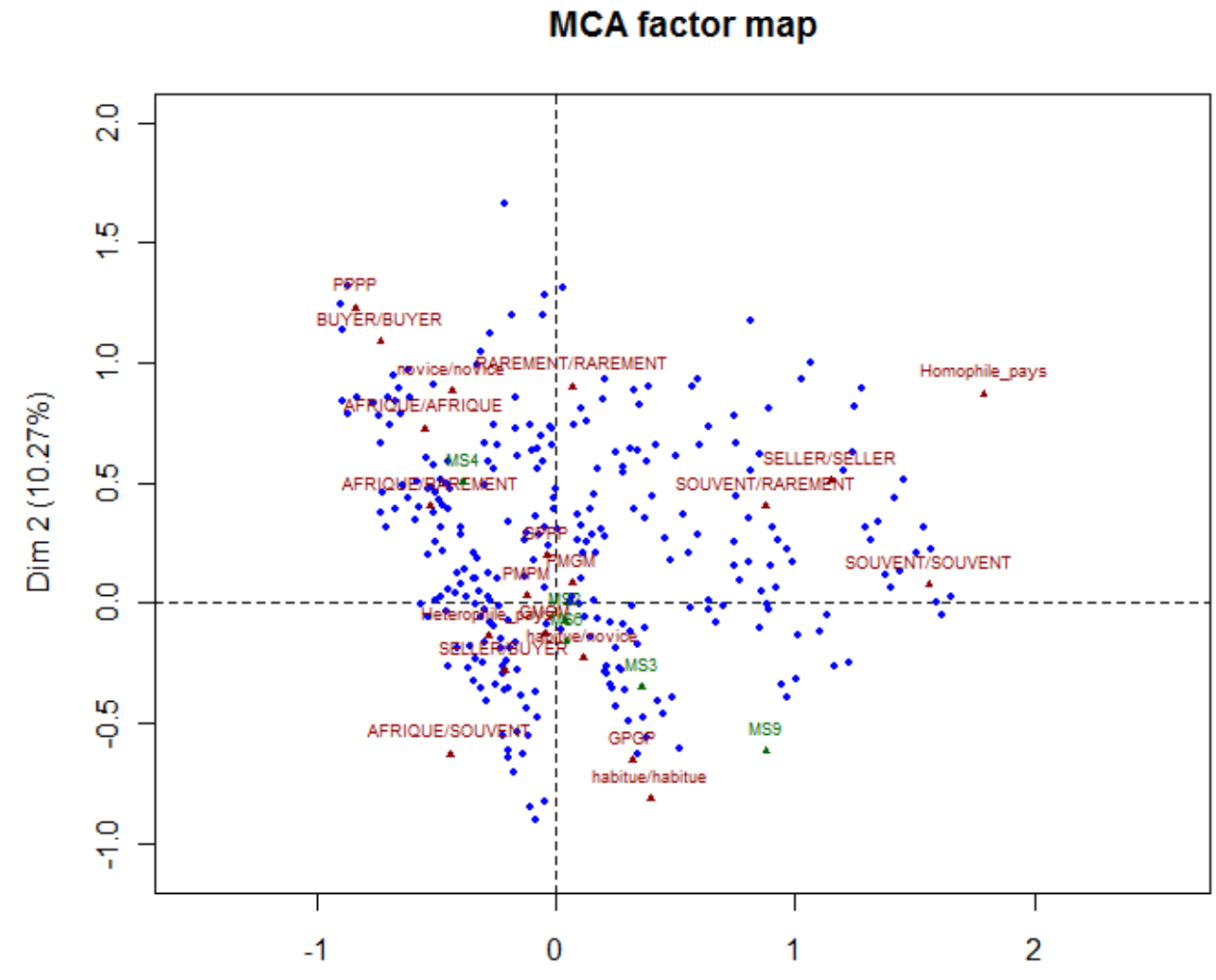

$\operatorname{Dim} 1(12.13 \%)$

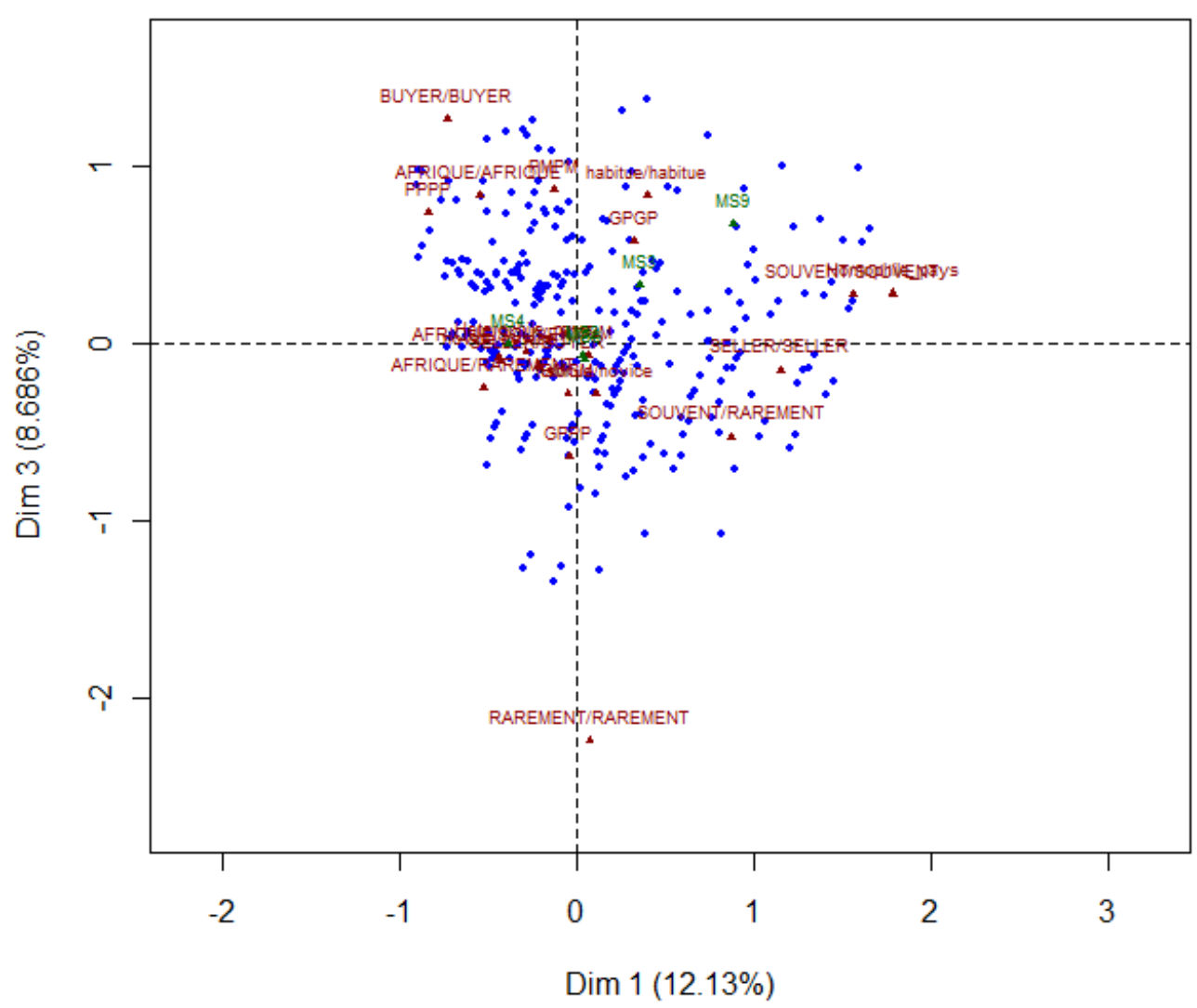



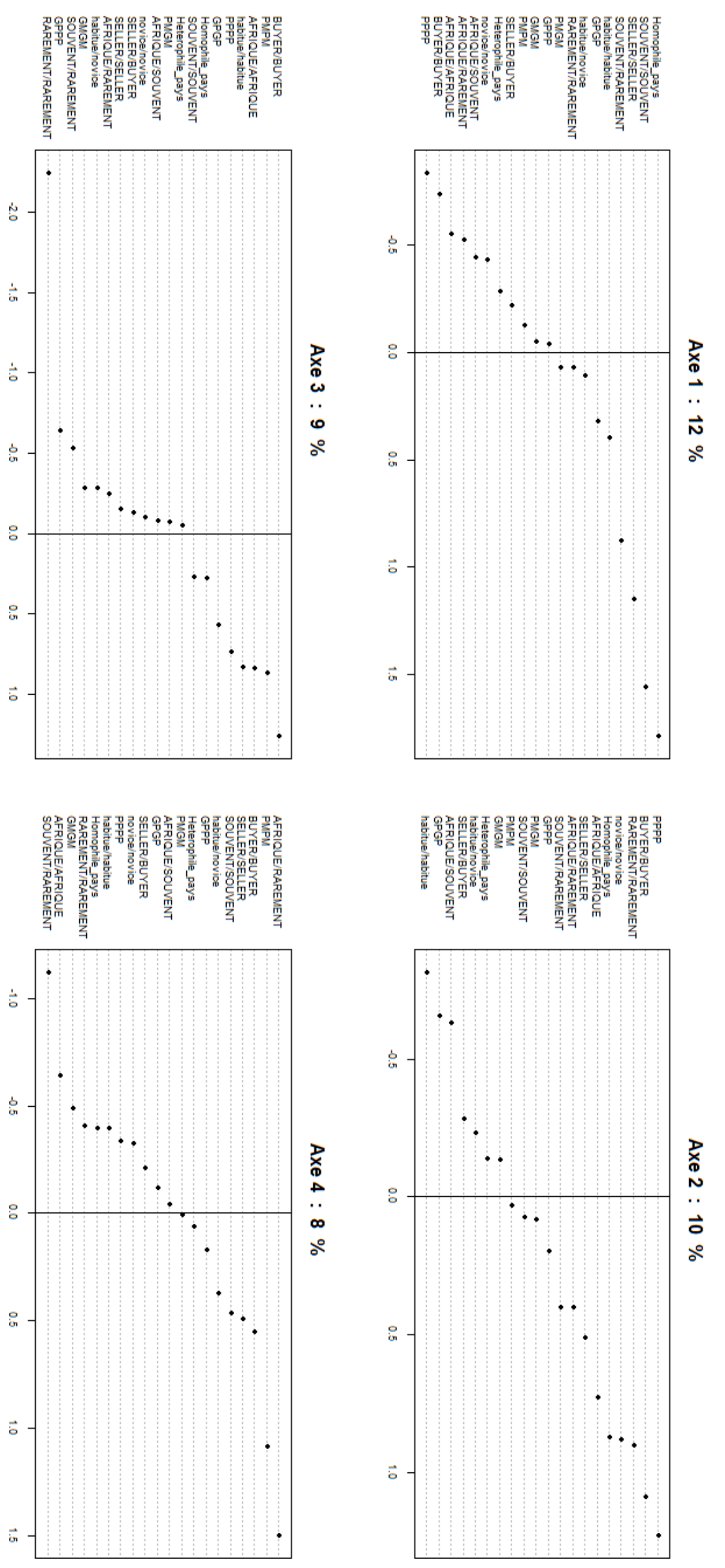

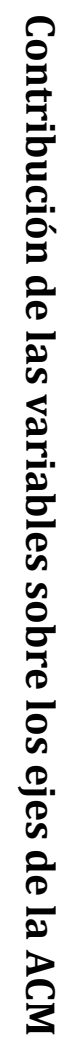

